\title{
Jesús Ramírez Cabañas (2011). Psicología en la cocina. Saber qué se cuece en nuestra mente para poner a punto nuestras emociones. Pontevedra: Ediciones Cydonia.
}

\author{
Jose A. León \\ Universidad Autónoma de Madrid, España
}

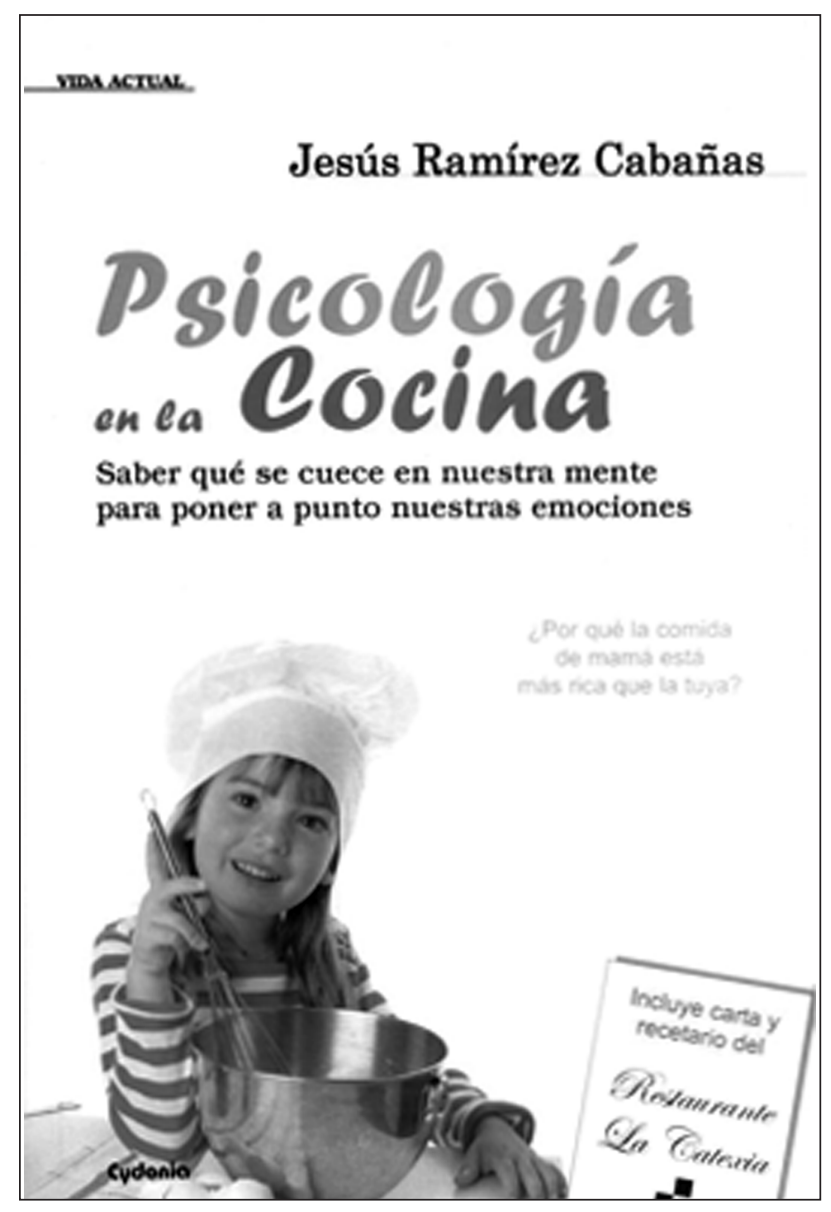

Las aplicaciones de la psicología parecen ser inescrutables. Este libro podría ser un claro ejemplo de estos tentáculos o raíces donde la psicología consigue adentrase o acabar germinando en un lugar muy distinto al de donde nació. De la misma manera que a la psicología le pertenece la vida mental, a la cocina le corresponde velar por aquellos placeres de la vida que penetran a través de nuestros sentidos. Lo que el autor consigue en esta obra es permeabilizar ambos mundos, como si de un proceso de ósmosis se tratase. De esta manera la propuesta de este libro parte de la idea de que la cocina, antaño el corazón del hogar, puede servir de base para llevar una vida saludable tanto física como mental. De esta manera, tal y como sostiene el autor, a quien cuece y amasa todo se le pasa, (una variante del refranero popular a quien cuece y amasa todo le pasa) es la base sobre la que se sostiene la filosofía de este libro. El cocinar como placer, como tónico relajante que nos aleje de los problemas diarios.

El libro está organizado en dos partes claramente diferencias. La primera, más psicológica, es donde el autor trata de relacionar las principales teorías tratando de determinar cuál es su relación con la cocina. En ella se proporciona un desglose de conceptos psicológicos y su relación con la cocina. De esta manera y dentro de esta primera parte, se despliegan una serie de pequeños capítulos dedicados, por ejemplo, a psicoanálisis y cocina (cap. 2), teorías del aprendizaje y cocina (cap.3) o a la psicología cognitiva y la cocina (cap.4). Si indagamos en esta primera parte el autor se plantea qué tiene que ver, pongamos por caso, comerse unas gambas al ajillo con la aplicación de un tratamiento cognitivo conductual. La relación se establece en el efecto que causan ambas, beneficio físico y mental. Pero, además, respecto al método que se lleva a cabo también existen paralelismos. Si bien es conocido que la psicología se basa en tres métodos fundamentales, el descriptivo, correlativo y experimental, el autor desvela que la cocina mantiene este mimetismo respecto a estos tres métodos. Así, mientras que un recetario de cocina es, básicamente, una descripción o formulación del plato, en su desarrollo requiere la valoración y control de multitud de variables que afectan a su resultado final, como son las cantidades, la temperatura del fuego, los tiempos de cocción, la combinación de ingredientes, etc. Esto ha dado lugar a lo que actualmente se conoce como laboratorios de cocina, ensalzados por grandes autores como Ferràn Adriá o Jose $\mathbf{M}^{\mathrm{a}}$ Arzak. Otros capítulos, en cambio, se concentran más en los sentidos, sensaciones y percepciones (cap.5), en la memoria (cap. 6) o la creatividad (cap.7). Esta primera parte finaliza con otros dos pequeños capítulos que introducen la toma de decisiones y solución de problemas (cap.8) y sobre el orden de las comidas (y en la psicología, cap.8). Todo escrito con un lenguaje desenfadado, ágil y cercano al lector. Esta cercanía se enaltece con la diseminación de pequeñas anécdotas por todo el itinerario de lectura, con lo que hace aún más participe al lector. Podríamos señalar que este libro también incluye "un anecdotario".

La segunda parte desarrolla la parte más "nutritiva" del libro, la que tiene más enjundia. Se trata de un recetario básico y muy elaborado con el que podremos 
deleitar a nuestros hijos, parientes o amigos. Cabe destacar aquí que se trata de un recetario de cocina con más de cien recetas elaboradas por el mismo autor y cuya elaboración no requiere de una habilidad especial. Como buen recetario dispone de una lista de entrantes, no más de una docena, pero repletos de imaginación, como el gazpacho de remolacha con crujiente de ibérico o las gambas del Faro de Cullera a los 35 segundos de cocción con mojo verde. Abundan, sin embargo, los platos de cuchara (fabes con almeja, patatas con costillas y níscalos), pescados (recomendamos el suquet de rape o el bonito a la plancha sobre stoemp de verduras), carnes y arroces (especialidad del autor, que las hace todas extraordinarias). Hay también un apartado a la cocina creativa (por si lo anterior no lo fuera) con títulos tan sugerentes como tortilla de patata deconstruida o croquetas liquidas de queso que, junto una media docena de postres muy sugerentes, harán la delicia de los comensales. Pero desde mi punto de vista, este libro guarda una agradable sorpresa y es un recetario especializado para niños y jóvenes con más de cincuenta recetas distribuidas en diferentes categorías como entrantes, pastas, de cuchara, huevos, pescados, carnes, postres, salsas, y hasta un apartado dedicado a la cocina rápida pero sana, por si la justificación del tiempo surge como excusa.

Da la impresión que al adentrase en sus páginas, este libro trata más bien de una biografía del autor que trata unir varios mundos apasionados: la vida, la psi- cología, la cocina y la escritura. Liga muy bien el ocio y el placer con el trabajo. Quizás por ello, Jesus Ramírez es, además de un profundo enamorado de la cocina, un profuso escritor, y un excelente psicólogo educativo, con más de treinta años de profesional a sus espaldas. Es autor de una docena de libros, entre los que se encuentra el Curso de Relajación Progresiva para niños y adultos, de la Editorial CEPE, el libro de texto para la materia optativa de Psicología de $2^{\circ}$ de Bachillerato, de la Editorial Almadraba, y la Guía del Embarazo de EOS, donde expone unos cuantos menús saludables para mantenerse bien durante el mismo. También participa activamente en el Colegio Oficial de Psicólogos de Madrid donde fue presidente de la Sección de Educativa y colabora asiduamente con medios de comunicación.

Examinando su propia experiencia no nos debe resultar extraño que trate de relacionar las principales teorías psicológicas con la cocina, de transmitirnos cómo puede reducirse el estrés y la ansiedad a través de los fogones, saber cómo influyen las comidas en nuestras percepciones y sensaciones o cómo podemos fomentar la creatividad y el razonamiento en la cocina. El deseo final del libro no puede ser otro que el lector o lectora consiga disfrutar comiendo y elaborando sus propias recetas, sabiendo que, además, está mejorando sus aspectos emocionales, reduciendo su estrés, y conociendo un poquito más de cerca una ciencia, como es la psicología. Toda una ciencia. 